\title{
The importance of arch geometry after Norwood reconstruction
}

\author{
Harold M. Burkhart, MD, ${ }^{\mathrm{a}}$ Jess L. Thompson, $\mathrm{MD},{ }^{\mathrm{a}}$ and Arshid Mir, $\mathrm{MD}^{\mathrm{b}}$
}

\author{
From the ${ }^{\mathrm{a}}$ Division of Cardiovascular and Thoracic Surgery, and ${ }^{\mathrm{b}}$ Section of Pediatric Cardiology, University of \\ Oklahoma Health Sciences Center, Oklahoma City, Okla. \\ Disclosures: Authors have nothing to disclose with regard to commercial support. \\ Received for publication April 10, 2017; accepted for publication April 13, 2017; available ahead of print May 9 , \\ 2017. \\ Address for reprints: Harold M. Burkhart, MD, Division of Cardiovascular and Thoracic Surgery, University of \\ Oklahoma Health Sciences Center, PO Box 26901, WP-2230, Oklahoma City, OK 73105 (E-mail: \\ Harold-burkhart@ouhsc.edu). \\ J Thorac Cardiovasc Surg 2017;154:1385-6 \\ $0022-5223 / \$ 36.00$ \\ Copyright (c) 2017 by The American Association for Thoracic Surgery \\ http://dx.doi.org/10.1016/j.jtcvs.2017.04.026
}

Life without geometry is pointless.

$$
\text { -Anonymous }
$$

Recoarctation of the aorta after Norwood reconstruction is associated with increased morbidity and mortality. Hill and colleagues ${ }^{1}$ reported a nearly 1 in 5 incidence of recoarctation intervention among the more than 500 patients evaluated in the Single Ventricle Reconstruction Trial. They also admitted that the frequency may have been underreported, given that patients who did not survive to prestage II evaluation might have had undiagnosed arch obstruction contributing to their demise. Those with recoarctation who did undergo pre-stage II evaluation had higher pulmonary arterial pressures, higher pulmonary vascular resistances, and increased right ventricular echocardiographic volumes.

In this issue of the Journal, Haller and colleagues ${ }^{2}$ report on their experience with aortic arch reconstruction in hypoplastic left heart syndrome and variants by means of the interdigitating technique. The principles of this reconstruction have been previously reported. ${ }^{3}$ In brief, the procedure involved complete mobilization of the arch vessels and proximal descending aorta in an effort to eliminate any tension. All coarctation and ductal tissues were aggressively excised. After spatulation of the proximal descending aorta anteriorly and posteriorly, the neoarch was reconstructed with an appropriately sized pulmonary homograft patch. All arch reconstructions were evaluated with key aortic measurements performed on left anterior oblique angiograms at pre-stage II and pre-stage III evaluations.

Overall, Haller and colleagues ${ }^{2}$ report that, although the reconstructed aortic geometry differed from that of a normal aorta, the diameters in all the aortic arch segments increased with growth. The $z$ scores were maintained in all segments, with the exception of the descending aorta, in which they became larger. There was evident tapering between the transverse and interdigitating segments, but recoarctation rate was very low $(4.1 \%)$. Interestingly, 4

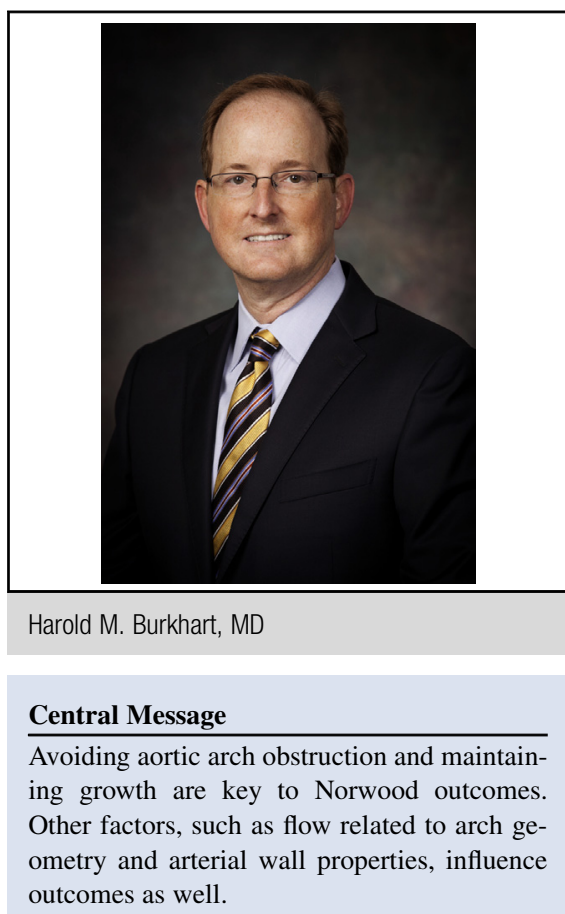

See Article page 1479 in the June 2017 issue.

(5.5\%) patients needed arch intervention for excessive arch dimensions.

The significance of the article of Haller and colleagues ${ }^{2}$ is twofold. Haller and colleagues ${ }^{2}$ have reported on a large single-institutional experience with a reproducible aortic arch reconstruction technique associated with low rates of recoarctation. In addition, even though the neoarch is not normal, they have demonstrated continued proportional growth.

There are a couple of limitations to the study. The first one, which Haller and colleagues ${ }^{2}$ acknowledge, is that 3-dimensional aortic arches are being evaluated with 2-dimensional lateral measurements. The use of 3-dimensional aortic data from computed tomography or magnetic resonance imaging could provide more accurate, comprehensive data with regard to aortic arch geometry. Another shortcoming is the lack of data regarding ventricular and atrioventricular valve function. One would assume that the risk of decreased ventricular function and increased valve regurgitation would be lower given the low recoarctation rate. With low recoarctation numbers and minimal 
information about the arches of the patients who did not survive, however, the inability to correlate the arch geometry with these outcomes is understandable.

In addition to avoiding aortic arch obstruction in Norwood reconstruction, there are other geometric arch factors that appear to influence outcomes. A mismatch in size between the aortic root and ascending aorta with a gothiclike transverse arch has been correlated with increased end-diastolic volumes and higher superior cavopulmonary pressures. ${ }^{4}$ In addition to the geometry of the arch, the neoaortic wall properties also affect patients with hypoplastic left heart syndrome and variants. A higher arterial elastance secondary to the presence of patch material in the reconstructed arch has been shown to impair ventricular function and ventriculoarterial coupling. ${ }^{5}$

In summary, the interdigitating technique results in low recoarctation rates while maintaining proportional aortic arch growth. The geometry of the arch associated with this reconstruction technique appears to be associated with exceptional surgical outcomes. Other factors, such as arterial wall properties and flow characteristics associated with arch geometry, will have to be considered when defining the ultimate aortic arch reconstruction.

\section{References}

1. Hill KD, Rhodes JF, Aiyagari R, Baker GH, Bergersen L, Chai PJ, et al. Intervention for recoarctation in the single ventricle reconstruction trial: incidence, risk, and outcomes. Circulation. 2013;128:954-61.

2. Haller C, Chetan D, Saedi A, Parker R, Van Arsdell GS, Honjo O. Geometry and growth of the reconstructed aorta in patients with hypoplastic left heart syndrome and variants. J Thorac Cardiovasc Surg. 2017;154:1479-87.e1.

3. Burkhart HM, Ashburn DA, Konstantinov IE, De Oliveira NC, Benson L, Williams WG, et al. Interdigitating arch reconstruction eliminates recurrent coarctation after the Norwood procedure. J Thorac Cardiovasc Surg. 2005; 130:61-5.

4. Bruse JL, Cervi E, McLeod K, Biglino G, Sermesant M, Pennec X, et al. Modeling of Congenital Hearts Alliance (MOCHA) Collaborative Group. Looks do matter! Aortic arch shape after hypoplastic left heart syndrome palliation correlates with cavopulmonary outcomes. Ann Thorac Surg. 2017;103:645-54.

5. Logoteta J, Ruppel C, Hansen JH, Fischer G, Becker K, Kramer HH, et al. Ventricular function and ventriculo-arterial coupling after palliation of hypoplastic left heart syndrome: a comparative study with Fontan patients with LV morphology. Int J Cardiol. 2017;227:691-7. 